\title{
Synthesis, Spectral and Thermal Properties of Bis Thiourea Zinc Acetate (BTZA) Single Crystals
}

\author{
Dr. J. Thomas Joseph Prakash \\ Assistant Professor, Department of Physics, \\ H.H. The Rajah's College (Autonomous), \\ Pudukkottai - 622 001, Tamilnadu, India.
}

\author{
L. Ruby Nirmala \\ Assistant Professor, Department of Physics, \\ Holy Cross College (Autonomous), \\ Trichy - 620 002, Tamilnadu, India.
}

\begin{abstract}
Bisthiourea Zinc Acetate (BTZA) a semi organic material has been synthesized by slow evaporation method using water as a solvent. The solubility studies have been carried out in aqueous solution in the temperature range $25{ }^{\circ} \mathrm{C}-45{ }^{\circ} \mathrm{C}$. Crystals have been grown from low temperature solution method by slow evaporation of saturated aqueous solution at room temperature. Single Crystal X-ray diffraction study has been carried out to determine the lattice parameter of the grown crystal. The spectral bands have been compared with similar thiourea complexes using FTIR spectrum in the range $400-4000 \mathrm{~cm}^{-1}$. Optical transmittance and absorption percentage of the grown crystal have been measured from UV-Vis studies. The thermal behavior has been investigated by thermogravimetric (TGA) and Differential Thermogram analyses (DTA). The mechanical strength and work hardening coefficient of the grown crystal have been analyzed by Vicker's microhardness method.
\end{abstract}

Keywords: Growth from solutions; X-ray diffraction; FT-IR; Optical transmission; Second harmonic generation; TGA/DTA.

\section{INTRODUCTION}

NLO materials play an important role in the field of fiber optic communication, laser technology, optical signal processing and also used in the area of opto-electronics, telecommunication, and optical storage devices [28] due to their potential applications in emerging optoelectronic technologies $[8,15,18,37,38]$. In order to satisfy the day-to-day technological requirements, many scientists focused their attention on the growth of materials which have a good nonlinear optical behavior and be optically transparent in the visible and near IR regions. Recent works shows that the organic crystals have been very large nonlinear susceptibilities than the inorganic one, but it has low laser damage threshold, inadequate transparency, poor optical quality, lack of robustness, inability to produce large crystals. In the case of Inorganic NLO materials, though they have excellent mechanical and thermal properties, they have relatively modest optical linearities due to the lack of extended $\pi$-electron delocalization $[21,23]$. Hence in last several years Research is focused on new types of NLO materials which combine the advantages of organic and inorganic materials called semiorganic materials. Two types of semiorganic material include organic and inorganic salts and metal organic coordination complexes [19, 27, 29, 30, 32, and 36]. Due to the high optical nonlinearity and chemical flexibility of organics combined with temporal and thermal stability and excellent transmittance in UV-
Visible region [27, 30, 32, and 36], the metal organic complexes have great attention in NLO field. The thiourea is an inorganic matrix modifier due to its large dipole moment and its ability to form an extensive network of hydrogen bonds [7]. The centrosymmetric thiourea molecule, when combined with inorganic salt yield noncentrosymmetric complexes, which has the nonlinear optical properties [2]. Growth and characterization of semiorganic crystals of Bisthiourea Zinc Acetate has already been reported $[10,12]$. Growth and characterization of pure and doped BTZA have already been reported [17]. Metastable zone width, induction period and interfacial energy of BTZA have also been reported [11]. In this paper, we are presenting some more characteristics of the BTZA crystals along with the reported studies.

\section{EXPERIMENTAL PROCEDURE}

\subsection{Solubility}

In the solution growth technique the size of a crystal depends on the amount of solute available in the solution which has been decided by the material present in that solvent [5]. The solubility of BTZA at a $\mathrm{pH}$ value 3.1 has been determined in the range $25{ }^{\circ} \mathrm{C}-45^{\circ} \mathrm{C}$. The solubility has been determined by dissolving the solute by continuous stirring in water in an airtight container maintained at a constant temperature to ensure homogeneous temperature and concentration throughout the volume of the solution. After reaching the saturation, the equilibrium concentration has been analyzed gravimetrically. The same process was repeated for different temperature values ranges from $25{ }^{\circ} \mathrm{C}$ to $45^{\circ} \mathrm{C}$. Figure 1 shows the solubility curve for BTZA at different temperature which shows that the solubility of BTZA increases significantly with increase in temperature in the growth region.

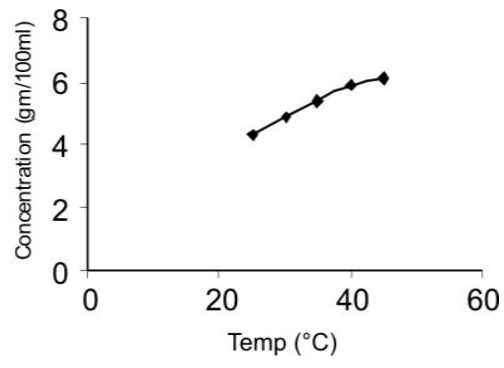

Figure 1 Solubility Curve of BTZA 


\subsection{Synthesis and crystal growth}

By mixing aqueous solutions of Zinc Acetate and thiourea in the stoichiometric ratio 1: 2 the BTZA salt has been synthesized. The following reaction estimates the required quantity of Zinc Acetate and thiourea:

\section{$\mathrm{Zn}\left(\mathrm{CH}_{3} \mathrm{COO}\right)_{2}+\left(\mathrm{NH}_{2} \mathrm{CS} \mathrm{NH}\right)_{2} \rightarrow \mathrm{Zn}\left(\mathrm{NH}_{2} \mathrm{CSNH}_{2}\right)_{2}\left(\mathrm{CH}_{3} \mathrm{COO}\right)_{2}$}

The required quantities of the component salts have been very well dissolved in double distilled water and thoroughly stirred to avoid the co-precipitation of the salts using a magnetic stirrer. Successive recrystallization process has been carried out to improve the purity of the synthesized salt. To avoid decomposition of the solute molecules, the mixer is to be heated not exceeding the temperature $50{ }^{\circ} \mathrm{C}$. The BTZA crystals were grown from aqueous solution by slow evaporation technique which is nonhygroscopic. Good optically transparent BTZA crystal has been crystallized with well defined faces in a period of 25 days which is shown in Figure. 2.

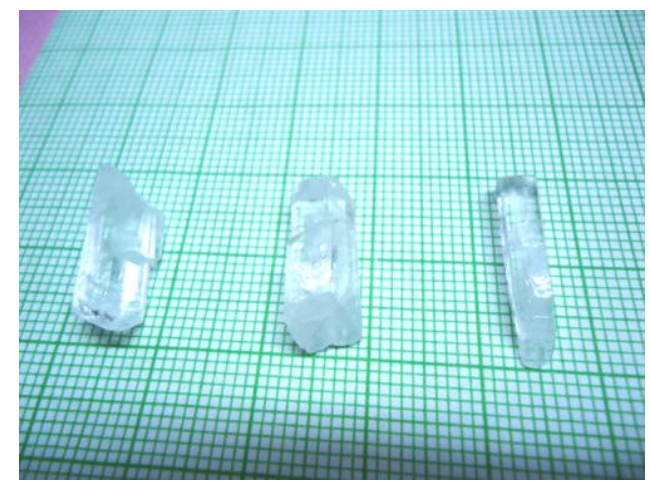

Figure 2 Photograph of as grown BTZA single crystal

\section{RESULTS AND DISCUSSION 3.1 Single crystal X-ray Diffraction}

The grown BTZA crystals have been subjected to single crystal $\mathrm{X}$ - ray diffraction studies using an ENRAF NONIUS CAD4 diffractometer with $\mathrm{MoK} \alpha$ radiation $\left(\lambda=0.71073 \mathrm{~A}^{\circ}\right)$ to determine the unit cell dimensions and morphology. The structures have been solved by the direct method and refined by the full matrix least square technique using SHELXL programme. The least square refinements of 25 reflections were done in the range $20^{\circ} \mathrm{C}$ $30^{\circ} \mathrm{C}$. The crystallographic parameters have been determined for BTZA is shown in the Table.1.

Table 1 Single crystal XRD Data of BTZA

\begin{tabular}{|c|c|}
\hline Chemical Formula & $\mathrm{Zn}\left(\mathrm{NH}_{2} \mathrm{CSNH}_{2}\right)_{2}\left(\mathrm{CH}_{3} \mathrm{COO}\right)_{2}$ \\
\hline Cell Parameters & $\mathrm{a}=7.129 \mathrm{~A}^{\circ}$ \\
\hline & $\mathrm{b}=17.708 \mathrm{~A}^{\circ}$ \\
\hline & $\mathrm{c}=11.189 \mathrm{~A}^{\circ}$ \\
\hline Volume & $1375.4 \mathrm{~A}^{3}$ \\
\hline Molecular Weight & 335.7 \\
\hline
\end{tabular}

This data agrees well with the literature values [10,12,and 16]. This has been confirmed by powder X-ray diffraction analysis by using a Rich Seifert diffractometer with $\operatorname{CuK} \alpha\left(\lambda=1.5417 \mathrm{~A}^{\circ}\right)$ radiation. This sample has been scanned over the range of $10{ }^{\circ} \mathrm{C}$
$-70{ }^{\circ} \mathrm{C}$ at a scan rate of $1 \%$ minute. The diffraction peaks were shown in Figure. 3.

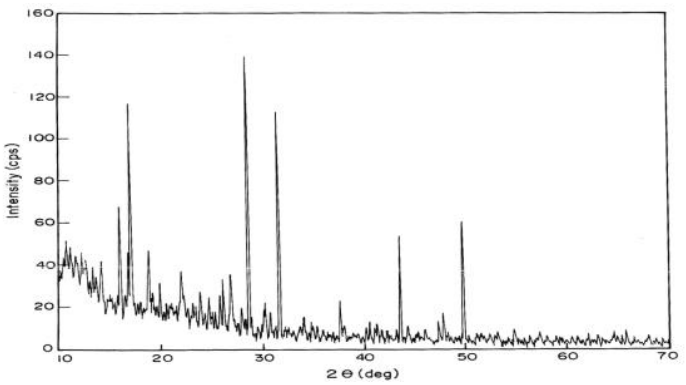

Figure 3 Powder X-Ray Diffraction pattern of BTZA

The unit cell parameters have been calculated using the TREOR programme which is shown in the Table. 2.

Table 2 Powder X-ray diffraction data for BTZA

\begin{tabular}{|c|c|c|c|c|c|c|c|}
\hline $\mathrm{D}$ & 2 Theta & $\mathrm{I}(\mathrm{rel})$ & $\mathrm{I}(\mathrm{abs})$ & FWHM & $\mathrm{h}$ & $\mathrm{k}$ & $\mathrm{l}$ \\
\hline 5.26189 & 16.8358 & 32 & 44 & 0.04 & -1 & 2 & 1 \\
\hline 5.169795 & 17.1379 & 87.7 & 121 & 0.12 & 0 & 3 & 1 \\
\hline 4.695257 & 18.8851 & 34.6 & 48 & 0.12 & -1 & 1 & 2 \\
\hline 4.451152 & 19.9311 & 23.5 & 32 & 0.08 & 0 & 4 & 0 \\
\hline 4.023639 & 22.0741 & 25.5 & 35 & 0.12 & 0 & 3 & 2 \\
\hline 3.721956 & 23.8886 & 19.6 & 27 & 0.08 & -1 & 4 & 0 \\
\hline 3.447758 & 25.82 & 18.3 & 25 & 0.12 & 0 & 4 & 2 \\
\hline 3.407639 & 26.1293 & 23.9 & 33 & 0.08 & 1 & 4 & 1 \\
\hline 3.315327 & 26.8703 & 24.6 & 34 & 0.12 & -1 & 2 & 3 \\
\hline 3.119825 & 28.5888 & 100 & 138 & 0.08 & -1 & 5 & 1 \\
\hline 2.95313 & 30.24 & 15.3 & 21 & 0.16 & 1 & 5 & 1 \\
\hline 2.909922 & 30.7 & 13.7 & 19 & 0.08 & 1 & 1 & 3 \\
\hline 2.824079 & 31.6573 & 84.9 & 117 & 0.08 & -2 & 1 & 3 \\
\hline 2.389342 & 37.615 & 17.1 & 24 & 0.12 & -2 & 4 & 3 \\
\hline 2.071177 & 43.6674 & 37.8 & 52 & 0.08 & 0 & 7 & 3 \\
\hline 1.898527 & 47.8744 & 11.7 & 16 & 0.08 & 2 & 2 & 4 \\
\hline 1.82615 & 49.8986 & 45.7 & 63 & 0.12 & -3 & 6 & 2 \\
\hline
\end{tabular}

\subsection{FT-IR Spectral Studies}

The Fourier Transform Infrared spectroscopy is effectively used to identity the functional groups present in the synthesized compounds. The powdered specimen of BTZA crystal has been subjected to FTIR analysis by PERKIN ELMER RXI Fourier Transform Infrared Spectrophotometer using $\mathrm{KBr}$ pellet technique in the wavelength range between 400 and $4000 \mathrm{~cm}^{-1}$. The observed bands along with their vibrational assignments have been tabulated in the Table.3. The recorded spectrum of BTZA is shown in the Figure 4. The FTIR spectrum of BTZA agrees well with the literature [1,12]. Crystal structure investigations of thiourea have established the coplanarity structure of C, N and S atoms in the molecule [1]. In the complex, due to the double centers for thiourea, there is a possibility to coordinate with zinc in two ways i.e., through nitrogen or sulfur [33] of thiourea. The high frequency N-H absorption bands in the region $3100-3400 \mathrm{~cm}^{-1}$ in the spectrum of thiourea have not been shifted to lower 
frequencies on the formation of metal thiourea complex which indicates that the bonding is only between sulfur and Zinc atoms and not of nitrogen and zinc [25]. The symmetric bending S-C-N stretching vibrations at $494 \mathrm{~cm}^{-1}$ of thiourea shifted to lower frequency at $448 \mathrm{~cm}^{-1}$ The symmetric and asymmetric $\mathrm{C}=\mathrm{S}$ stretching vibrations at 730 and $1417 \mathrm{~cm}^{-1}$ of thiourea are shifted to low frequency region at 677 and $1403 \mathrm{~cm}^{-1}$ in BTZA respectively which confirms the formation of metal sulphur coordination band [33]. $\mathrm{C}=\mathrm{S}$ stretching vibration at $1089 \mathrm{~cm}^{-1}$ is shifted to higher frequency $1130 \mathrm{~cm}^{-1}$ shows the binding of zinc with thiourea is through sulphur [12]. $\mathrm{NH}_{2}$ bending at $1627 \mathrm{~cm}^{-1}$ is shifted to higher frequency region at $1644 \mathrm{~cm}^{-1}$, asymmetric bending of $\mathrm{NH}_{2}$ at $3376 \mathrm{~cm}^{-1}$ of thiourea shifted to lower frequency region at $3310 \mathrm{~cm}^{-1}$. The stretch vibrations of BTZA are compared with the available data for thiourea [12].

Table 3 Assignment of IR band frequencies $\left(\mathrm{cm}^{-1}\right)$ of thiourea and BTZA

\begin{tabular}{|c|c|ll|}
\hline $\begin{array}{c}\text { Thiourea } \\
\left(\mathrm{cm}^{-1}\right)\end{array}$ & $\begin{array}{c}\text { BTZA } \\
\left(\mathrm{cm}^{-1}\right)\end{array}$ & \multicolumn{2}{|c|}{ Assignment } \\
\hline 494 & 480 & $\mathrm{~S}-\mathrm{C}-\mathrm{N}$ & symmetric bending \\
\hline 730 & 677 & $\mathrm{C}=\mathrm{S}$ & stretching \\
\hline 1089 & 1130 & $\mathrm{C}=\mathrm{S}$ & stretching \\
\hline 1417 & 1403 & $\mathrm{C}=\mathrm{S}$ & asymmetric stretching \\
\hline 1627 & 1644 & $\mathrm{NH}_{2}$ & bending \\
\hline
\end{tabular}

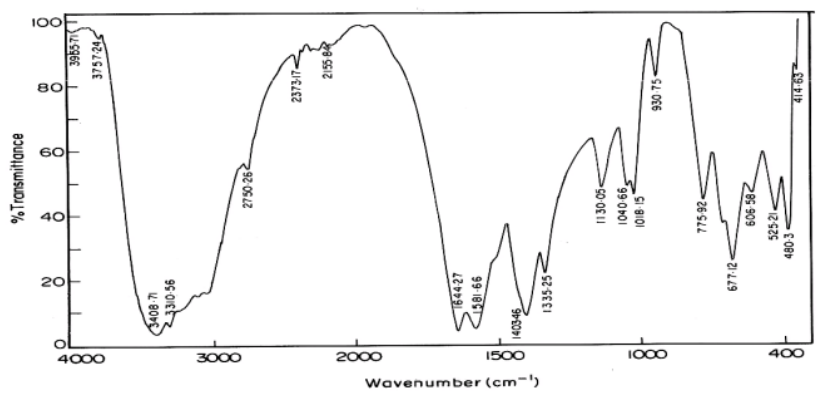

Figure 4. FTIR Spectrum of BTZA

\subsection{Optical Transmission Studies}

Transmission spectra are very important for any NLO material because an NLO material can be used for practical purposes only if it has a wider transparency window. To determine the suitability and transmission range of the BTZA single crystal for optical applications, the UV-Visible spectrum has been recorded in the range $200-1200 \mathrm{~nm}$ by using LAMBDA-35 UV-Vis spectrometer. The crystal is well polished and the specimen of $3 \mathrm{~mm}$ thick has been subjected to transmission measurements in the spectral region. The recorded spectrum is shown in the Figure.5. The lower cutoff wavelength is around 260 $\mathrm{nm}$. This $\pi$ electron dislocation is responsible for its nonlinear optical responses and absorption in near UV region [34]. Thus the grown crystal has got a good transmission in UV as well as in visible region $260-1100 \mathrm{~nm}$. The wide range of transparency of grown crystal is an added advantage in the field of optoelectronic application [3].

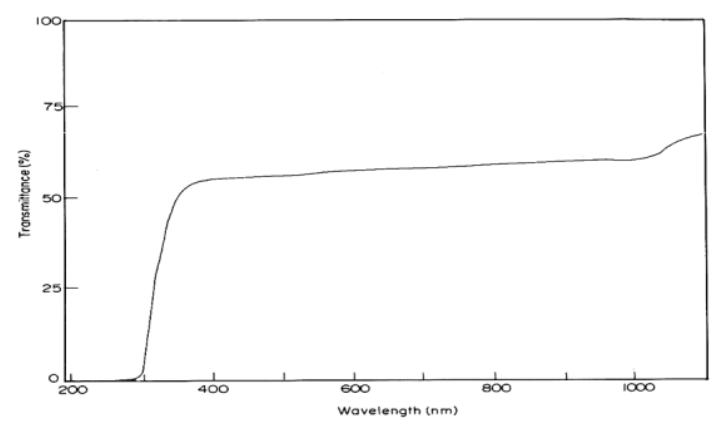

Figure $5 \mathrm{UV}-\mathrm{Vis}$ spectrum of BTZA

\subsection{Second Harmonic Generation Test}

The fundamental beam of $1064 \mathrm{~nm}$ from Q-Switched Nd: YAG laser Prolab170 Quanta ray has been used to test the SHG property of BTZA single crystal by the Kurtz and Perry technique [14].

\subsection{Thermal Studies}

Differential Thermogram analysis (DTA) and thermogravimetric analysis (TGA) give information regarding phase transition, water of crystallization and different stages of decomposition of the crystal system [20]. The TGA is carried out between $20{ }^{\circ} \mathrm{C} / \mathrm{min}$ using Perkin-Elmer thermal analyzer STA409PC. Figure. 6. Shows the DTA \& TGA spectra of BTZA crystal. Below $180{ }^{\circ} \mathrm{C}$ there is no detectable weight loss and hence crystal rejects solvent molecules during crystallization, which shows that there is no decomposition upto melting point and this insures thermal stability of material for possible application in Lasers. These curves show that the loss of weight occurs in three steps. The first weight losses in $57.46 \%$ are due to the decomposition of both compounds and the second weight loss occurs due to organic compound evaporation in $14.42 \%$ and the third weight loss occurs due to the residue at $24.91 \%$. According to the results of thermal analysis of some metal-thiourea complexes the residue is most likely $\mathrm{ZnS}$, $\mathrm{CdS}$ or $\mathrm{ZnO}, \mathrm{CdO}$ [9]. From the DTA curves, two endothermic peaks have been observed at $164{ }^{\circ} \mathrm{C}$ and $211{ }^{\circ} \mathrm{C}$. The first endothermic peak has been assigned to the melting point of BTZA and the second peak is due to the decomposition stage of BTZA and there has been no endothermic or exothermic peak below its melting point. Above $164{ }^{\circ} \mathrm{C}$, there is no peak in TGA spectrum which shows the residue of BTZA have been a stable one.

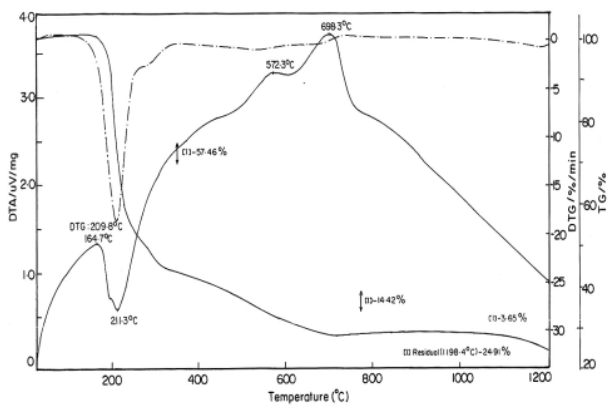

Figure 6 TG / DTA Curves of BTZA 


\subsection{Mechanical Property}

Hardness is a measure of the resistance to plastic deformation [24]. This permanent deformation can be achieved by indentation, bending, scratching or cutting. The hardness of the crystal carries information about the strength, molecular bindings, yield strength and elastic constants of the material. The Mechanical property of the BTZA crystals has been studied using LEITZ microhardness tester, fitted with a Vickers's diamond pyramidal indenter. A well polished BTZA crystal has been placed on the platform of Vickers microhardness tester and the loads of different magnitudes have been applied in a fixed interval of time. The indentation time has been kept 8 seconds for all the loads. Vickers microhardness values have been calculated by using the formula $\mathrm{Hv}=1.8544 \mathrm{x}$ $\mathrm{P} / \mathrm{d}^{2} \mathrm{Kg} / \mathrm{mm}^{2}$. Where $\mathrm{Hv}$ is the Vickers microhardness number, $\mathrm{P}$ is the applied load in $\mathrm{Kg}, \mathrm{d}$ is the mean diagonal length of the indentation impression in $\mathrm{mm}$ and 1.8544 is a constant of a geometrical fraction for the diamond pyramid. The hardness values have been taken for various applied loads over a fixed interval of time. A graph has been plotted between hardness number (Hv) and applied load (P) as shown in the Figure. 7. At lower loads there is an increase in the hardness with load, which can be attributed to the work hardening of the surface layers. At higher loads, the 'Hv' shows the tendency to saturate. Beyond the load of 100 gm significant cracking occurs which may be due to the release of internal stresses generated locally by indentation [35]. Higher the harness values, grater the stress required to form dislocation, thus confirming greater crystalline perfection. Hence it may be suggested that the material may be used for the device below the applied load of $100 \mathrm{gm}$. The relation connecting the applied load (P) and diagonal length (d) of the indenter is given by the Meyer Law [22]. $P=\operatorname{ad}^{n}$ where ' $n$ ' is the Meyer index or work hardening coefficient and ' $\mathrm{a}$ ' is the constant for a given material. A graph has been plotted between $\log (\mathrm{P})$ Vs $\log (\mathrm{d})$ as shown in the Figure. 8. The slope of the straight line by least squares fit method gives Meyer index number / work hardening index as 3.6. $\mathrm{Hv}$ should increase with the increase of $\mathrm{P}$ if $\mathrm{n}>2$ and decrease if $\mathrm{n}<2$. From the observations on various materials Onitschnn [26] and Hanneman [6] pointed out that ' $n$ ' lies between 1 and 1.6 for moderately hard materials, and it are more than 1.6 for soft material. The slope of 3.6 reveals that the material has a higher hardness coefficient and it is useful for non-linear optical applications.

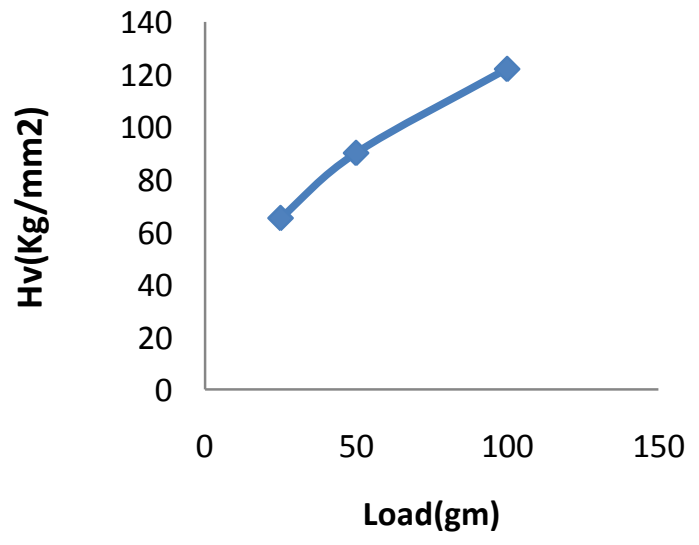

Figure 7 Vickers hardness number with load for BTZA

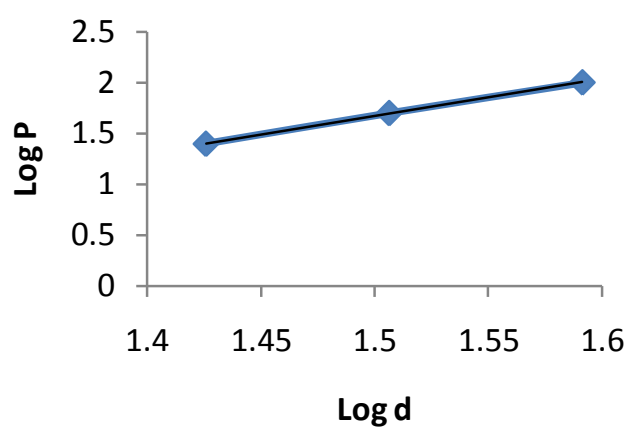

Figure 8 Graph between Log P Vs Log d

\subsection{Etching Studies}

To obtain the structural perfection and growth features of a grown crystal, etching studies can be used. The (100) plane of the BTZA crystal has been completely immersed for $5 \mathrm{~s}$ and $10 \mathrm{~s}$ in the water etchant and the sample was wiped out with dry filter paper. Using a Magnus MLX Microscope the features of the crystal has been analyzed which is shown in the Figure 9(a), 9(b). The same procedure has been repeated for another etchant like ethanol which is shown in Figure 9(c), 9(d). From the figures, number of etch pits have been identified with identical shape. By increasing the etching time, the pattern remains the same but the size of the etch pits have been increases. The etch pit can be attributed to the initial dislocations formed at low angle boundaries or segregated impurities. The etch pits did not appear upon continuous etching suggesting that the pits were due to dislocations [31] which is strongly correlated to the formation of inclusions in the crystals which can be originate from growth sector boundaries [4]. Also due to the liquid inclusions there have been drastic changes in growth condition [13]. In General, it is observed that the less number of dislocations shows the quality of the crystal.

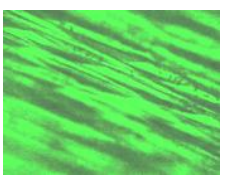

Figure 9(a)

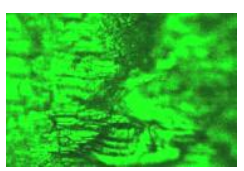

Figure 9(c),
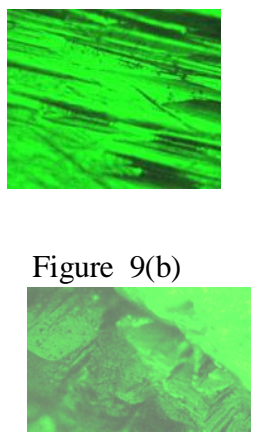

Frigure 9(d)

\section{CONCLUSION}

The good quality nonlinear optical Semi-organic single crystals of BTZA have been successfully synthesized and the crystals have been grown by solution growth technique using water as the solvent. Solubility of BTZA was estimated for different temperatures. The structure is confirmed with Single Crystal X-ray 
analysis and its lattice dimensions have been determined from the powder X-ray diffraction analysis. The various functional groups present in BTZA are analyzed by FTIR Spectrum and it has been found that there is a shift in the frequency band in low frequency region which reveals that the thiourea forms acetate-to-zinc bonds in the BTZA crystal. The transparency nature of the crystal in the Visible and Infrared regions was $260-1100 \mathrm{~nm}$ that forms the transmission spectrum and it confirms the NLO property of the crystal. It has a lower UV cutoff of $260 \mathrm{~nm}$ and has a transmittance of $60 \%$. From the TGA and DTA curves, the sample is highly stable upto $209{ }^{\circ} \mathrm{C}$ which indicates that the material is thermally stable and its melting point is found to be $164{ }^{\circ} \mathrm{C}$. Hence it may be useful for SHG applications below its melting point. Mechanical strength of the crystal has been studied by Vickers microhardness measurements. The crystal perfections and quality have been identified by using the etching studies.

\section{REFERENCES}

[1] Andreeti G.D, Cavalca L, Musatti A, Acta Crystallogr. B24 (1968)683.

[2] Anie Roshan S, Joseph C, Ittachen M.A., Mater.Lett.49 (2001)299.

[3] Bairava Ganesh R, Kannan V, Sathyalakshmi R, Ramasamy P. Mater. Lett. 61(2007) 706.

[4] Bhat H.L, Prog. Crystal Growth and Charact. 11 (1985) 57.

[5] Christian R, Solvents and Solvents Effects Inorganic chemistry, VCH, NewYork, 1990.

[6] Hanneman M, Metall, Manch. 23 (1941) 135.

[7] Hellwege K.H, Hellwege A.M, Landolt-Bornstein, Group II 14 (1982)584.

[8] Iwai M, Kobayashi T, Furya H, Mori Y, Sasaki T, Jpn.J.Appl.Phys. 36(1997)1.276.

[9] Janos Madarasz, Petra Bombicz, Masayuki Okuya, Shoji Kaneko, Solid State Ionics 439 (2001)41.

[10] Jayalakshmi D, Kumar J, Cryst.Res.Technol.41 (2006)37.

[11] Jayalakshmi D, Sankar R, Jayavel R, Kumar J, J.Cryst.Growth 276(2005)243-246.

[12] Kannan V, Rajesh N.P, Bairava Ganesh R, Ramasamy P, J.Cryst.Growth 269(2004)565.

[13] Krishnan Rao K, Surender V,Bull. Mater.Sci. 24 (2001) 665.

[14] Kurtz S.K, Perry T.T.. J. Appl. Phys. 39 (1968) 3798.

[15] Ledoux L synth.Metal 54(1993)123.

[16] Luigi Cavalca, Giovanna Fava Gasparri, Giovanni Dario Andreetti, Paolo Domiano Acta Cryst.22 (1967)90.

[17] Lydia Caroline M, Vasudevan S, Current applied physics 9(2009)1054.
[18] Marey H.O, Warren L.F, Webb M.S, Ebbers C.A, Velsko S.P, Kennedy G.C, Catella G.C, Applied Opts.31 (1992)5051.

[19] Meera K, Muralidharan R, Dhanasekaran R, PrapunManyum, Ramasamy P, J.Cryst.Growth 263(2004)510.

[20] Meng F, Lu M.K, Yang, Zeng H., Mater. Lett. 33(1998) 265.

[21] Mercy H.O, Rosker M.J, Warren L.F, Cunningham P.H, Thomas C.A, Deloach L.A, Velsko S.P, Ebbers C.A, Liao J.H, Kanatzidis M.G, Opt.Lett.20 (1995) 252.

[22] Meyers M.A, some aspects of the hardness of metals, Ph.D., Thesis, Dreft, (1951)

[23] Mohankumar R, Rajan Babu D, Ravi G, Jayavel R, J.Cryst.Growth 250(2003)113.

[24] Mott B.W, Micro indentation Hardness Testing, Butterworth London (1956)

[25] Nakamoto K, IR Spectra of Inorganic and Co-ordination Compounds. IIEd, Wiley, New York, 1978.

[26] Onitsch E.M, Mikroscopia 2 (1947) 131

[27] Pracilla Jeyakumari A, Ramajothi J, Dhanuskodi S, J.Cryst.Growth 269(2004)558.

[28] Prasad P.N and Williams D.J, Introduction to Nonlinear Optical Effects in Molecules and polymers Wiley Interscience, New York, 1991.

[29] Raja Sekaran R, Ushasree P.M, Jayavel R, Ramasamy P, J.Cryst.Growth 229(2001)563.

[30] Ramajothi J, Dhanuskodi S, Nagarajan K, Cryst. Res. Technol. 39(2004)414.

[31] Senthil Pandian M, BalaMurugan N, Bhagavannarayana G, Ramasamy P, J.Crys.Growth 10 (2008) 4143-4147.

[32] Sun H.Q, Yuan D.R, Wang X.Q, Cheng X.F, Gong C.R, Zhou M, Xu H.Y, Wei X.C, Luan C.N, Pan D.Y, Li Z.F, Shi X.Z, Cryst.Res.Technol.40 (2005)882.

[33] Swaminathan K, Irving H.M.N.H, Inorg J, Nucl. Chem. 26(1964)1291

[34] Ushasree P.M, Jayavel R, Ramasamy P, Mater. Sci. Eng. B65 (1999)153.

[35] Ushasree P.M, Jayavel R, Subramanian C, Ramasamy P, Bull.Electorchem.14 (1998)407.

[36] Ushasree P.M, Muralidharan R, Jayavel R, Ramasamy P, J.Cryst.Growth 218(2000)365.

[37] Wang X.Q, Xu D, Yuan D.R, Tian Y.P, Yu W.T, Sun S.Y, Yang Z.H, Fang Q, Lu M.K, Yan Y.X, Meng F.Q, Guo S.Y, Zhang G.H, Jiang M.H, Mater.Res.Bull.34 (199) (2003).

[38] Yuan D.R, Xu D, Zhang N, Liu M.G, Jiang.Chin M.H, Phys.Lett.13 (1996)841. 